\title{
New truths begin as heresies: first thoughts on system dynamics and global modelling
}

Article

Accepted Version

Lane, D. (2019) New truths begin as heresies: first thoughts on system dynamics and global modelling. Systems Research and Behavioral Science, 36 (2). pp. 233-243. ISSN 1099-1743 doi: https://doi.org/10.1002/sres.2585 Available at https://centaur.reading.ac.uk/82435/

It is advisable to refer to the publisher's version if you intend to cite from the work. See Guidance on citing.

To link to this article DOI: http://dx.doi.org/10.1002/sres.2585

Publisher: Wiley

All outputs in CentAUR are protected by Intellectual Property Rights law, including copyright law. Copyright and IPR is retained by the creators or other copyright holders. Terms and conditions for use of this material are defined in the End User Agreement.

www.reading.ac.uk/centaur 
Central Archive at the University of Reading

Reading's research outputs online 


\title{
New Truths Begin as Heresies: First thoughts on system dynamics and global modelling
}

\author{
David C Lane
}

Correspondence to: Prof David C Lane, Henley Business School, Whiteknights, Reading, RG6 6UD, England.

$$
\text { E-mail: d.c.lane@henley.ac.uk }
$$

\section{Repository Note}

This document is the accepted version of the following article:

Lane DC. 2019. New Truths Begin as Heresies: Thoughts on system dynamics and global modelling. Systems Research and Behavioral Science 36(2): to appear.

Note that the published version may have some differences from the version here. In all cases, the published version takes precedence.

If you wish to cite the ideas in this paper then please cite the version published in $S R \& B S, N O T$ this version.

Please contact the Corresponding Author if you have any queries. 


\title{
New Truths Begin as Heresies: First thoughts on system dynamics and global modelling
}

\author{
David C Lane BSc MSc DPhil FORS \\ Henley Business School, Reading, UK
}

Starting from an example of biosphere modelling, the paper considers the contribution of System Dynamics to global modelling. The different purposes of modelling approaches are first considered. These are then related to a specific example - which is then seen to derive from the founding works in this area: 'World Dynamics' and 'The Limits To Growth'. The response to those publications is considered along with contemporary reactions to them and the myths that have grown up around them. The paper discusses the continuing - and decidedly mixed - significance of these works to the field of System Dynamics.

Keywords: system dynamics; global modelling, simulation modelling; World Dynamics, The Limits To Growth, socio-technical systems.

\section{INTRODUCTION}

The theme of this special issue (and of the 2017 workshop in Lisbon from which it is derived) is 'Modelling Sustainability Pathways: Bridging science, policy and society'. Fundamentally, the reasons for using modelling to explore issues in this area do not differ conceptually from those in other domains of application. However, there are some quite distinctive and interesting features and these merit discussion. This piece aims to outline some of these and then explore some aspects of the broad reaction to the first forays of system dynamics into the area of global modelling.

The first section considers the role of models and illustrates this with an example; this shows some of the distinctive features of modelling work for global issues. The second section goes back to the 1970s, to the publications in the system dynamics field which laid the groundwork for global modelling studies, and traces some of the reactions to them. The penultimate section considers the modern perspective on these efforts and the paper closes by pondering their continuing influence on the field of system dynamics.

\section{MODELS AND GLOBAL MODELLING}

The various different roles of models are briefly discussed and then illustrated with an example. In terms both of methodology and contribution to a specific domain, this serves to reveal some of the distinctive features of modelling work undertaken to consider global issues and thereby echoes the system dynamics work that founded the area of global modelling.

\section{On Modelling Methodology}

What forms models take and what they can be used for is a well-trodden area of discussion within all modelling communities and across science generally. A guide for the layperson is available (Government Office for Science, 2018, 'Chapter 1: Why model?') and a simple reprise of this complex territory will suffice here. 
Whether it be a cardboard model of a proposed building, or an algebraic calculation of an annuity calculation, or a multi-dimensional mathematical/calculus representation of a new aircraft design, ${ }^{1}$ a model is an abstraction that is derived from many different sources and motivations. Similarly, a model can be framed to act in different ways, and be designed to produce different outputs (Fig. 1). It can be used to generate answers to specific questions by providing specific results: given these personal characteristics, what might a pension be worth? Viewed from the North West, does this building's portico have the desired effect? A model can be used as an exploratory device to play with different policies, thereby providing general insights: what control surfaces are best used to effect rapid manoeuvres? Do the short term consequences of using this policy lever differ from the longer term consequences? Perhaps more subtly, a model can be used as a research instrument, a rigorous means of scoping some phenomenon to further one's understanding of what needs to be modelled and how. In this instance the modelling process is addressing the question: the following mechanisms might exist but do they matter, do they have important consequences? Finally, a model can - by design or accident - have broader effects by serving to challenge existing assumptions and worldviews.

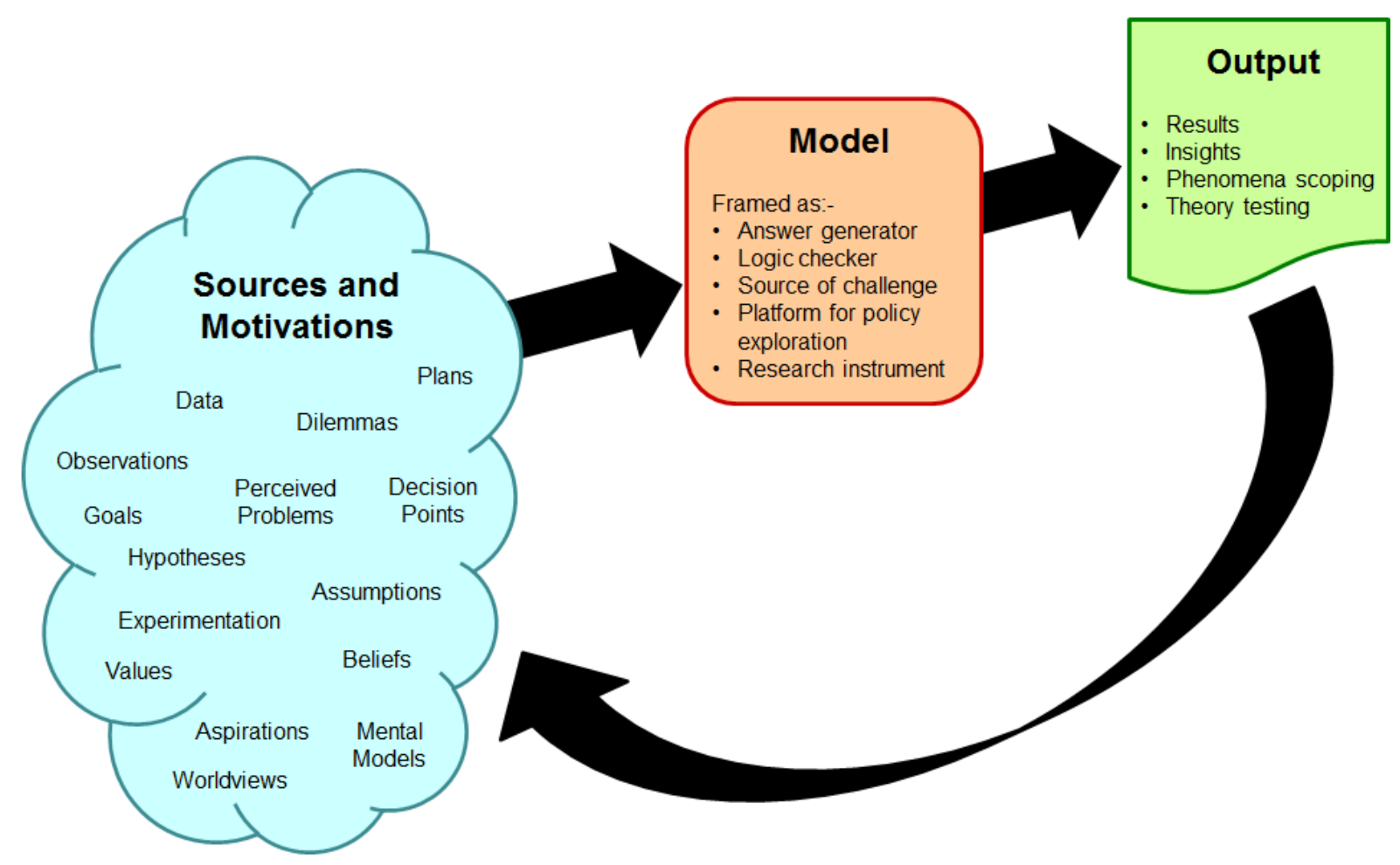

Fig. 1. The Modelling Cycle: sources, framing and output.

In principle, all models facilitate a cycling back to the sources and motivations from which they were derived. However, global modelling work provides a particularly compelling example of this cycling,

\footnotetext{
${ }^{1}$ This is a reference to ASCA (Aircraft Stability and Control Analyzer), a mid-to-late 1940s device which aimed to use servo-mechanism and analogue computing technologies to create a simulator for new aircraft designs. The idea was that by 'test- flying' the designs the behaviour of the proposed aircraft could be learned about in a direct, experiential way. Jay Forrester was the director of this project, and it has been argued that the experience informed his subsequent creation of system dynamics, with its core idea of organisational design using computer simulation (Lane, 2007).
} 
of how modelling can achieve effects much broader than the generation of results or even the creation by exploration of insights.

This description may seem abstract but to illustrate the idea, and to show how it leads to specific domain understanding, the work by Lade et al. (2017) is next considered.

\section{Modelling to Exploring the Relevance of Carbon Cycle Feedbacks}

The Lade et al. (2017) paper concerns the ability of the combined terrestrial and marine biosphere to act as sinks for emissions of fossil fuels. The biosphere's capacity to sink carbon depends on biodiversity but its operation is by no means fully understood. Specifically, the paper explores the importance of including four 'climate feedback effects' in the interaction of climate and the sinks of the atmosphere, the oceans and the land. Two effects have balancing loop polarities: increased atmospheric carbon generates increased carbon uptake on both land (via the 'fertilisation effect' of increased $\mathrm{CO}_{2}$ stimulating flora) and also the oceans (the 'partial pressure' effect of increased $\mathrm{CO}_{2}$ increasing ocean absorption). These loops therefore tend to equilibrate the effects of human emissions. However, two others have reinforcing loop polarities: as higher atmospheric $\mathrm{CO}_{2}$ increases temperature via radiative forcing there is decreased land storage (because of increased respiration rates from plants and soil) and decreased ocean storage (as $\mathrm{CO}_{2}$ becomes less soluble). These therefore operate in a manner which tends to amplify the effects of human emissions.

The paper is technically complex but conceptually straightforward. It accepts that the underlying mechanisms of these four effects are thought to exist, includes a first-cut representation of them in a stylised model, offers a cautious parameterisation of them, and then uses simulations to see whether their inclusion has significant consequences. It does this by considering what extra warming results from a range of factors, including each of the four feedback effects, and in doing so generates useful domain and methodological contributions.

The authors find that, "... interactions between these boundaries [biosphere integrity and climate change] can indeed reduce the extent to which humanity can emit carbon dioxide or interfere with biosphere integrity" (ibid., p. 11). In other words, having scoped the phenomena, it looks as though these feedback mechanisms do matter. They conclude that more work involving these mechanisms is justified; "More research is needed to understand how carbon storage in different ecosystems will respond to climate change and to biodiversity loss. Likewise, climate policy and biodiversity policy which are currently strongly separated - should in future be analysed" (loc. cit.).

\section{Back To The Roots Of Global Modelling}

In a notable step, these authors go on to place their study within the discourse of the 'planetary operating space', or 'planetary boundaries' (Rockström, et al., 2009). These boundaries concern natural science effects, nine in all, and illustrate that in terms of rate of biodiversity loss and the limits of the Nitrogen cycle, humanity has moved beyond that 'operating space'. Lade et al. make that connection, build on that idea and add to theory by re-emphasising the importance of including feedback effects in any future hypotheses and hence models. In this way, the cycle of Fig. 1 is enacted.

The same methodological point applies to other pieces in this special issue and to 'global modelling' work generally. As stated, there is something distinctive about this area. This is seen in one last feature of the work by Lade et al.

So far the reader may feel that the phenomena under consideration are purely physical, there are no active agents or social elements included in the modelling. Surely this is not system dynamics but 
merely the use of ordinary differential equations? This feeling is false. The authors also suggest that; "Future research on interactions between planetary boundaries should also consider interactions with the social boundaries identified by Raworth (2012)" (Lade et al., p. 11). This is a key step. The paper referenced in that quotation contains an 11-dimensional 'social doughnut' (Raworth, 2012; see also Dearing, et al., 2014). It presents a 'safe and just space for humanity', an American doughnut shape within an outer ring of nine physical dimensions of the environmental ceiling derived from Rockström et al., and an inside consisting of 11 elements of 'social foundations' (see Fig. 2). This is modelling which seeks to understand the broader interaction of natural effects and those grounded in social/human behaviour, and to craft an appropriate set of goals and aspirations. It also offers a challenge to ideas about humanity's place in the planetary eco-systems and in this way serves to challenge mental models and deeply-held assumptions, beliefs and worldviews (see Fig. 1).

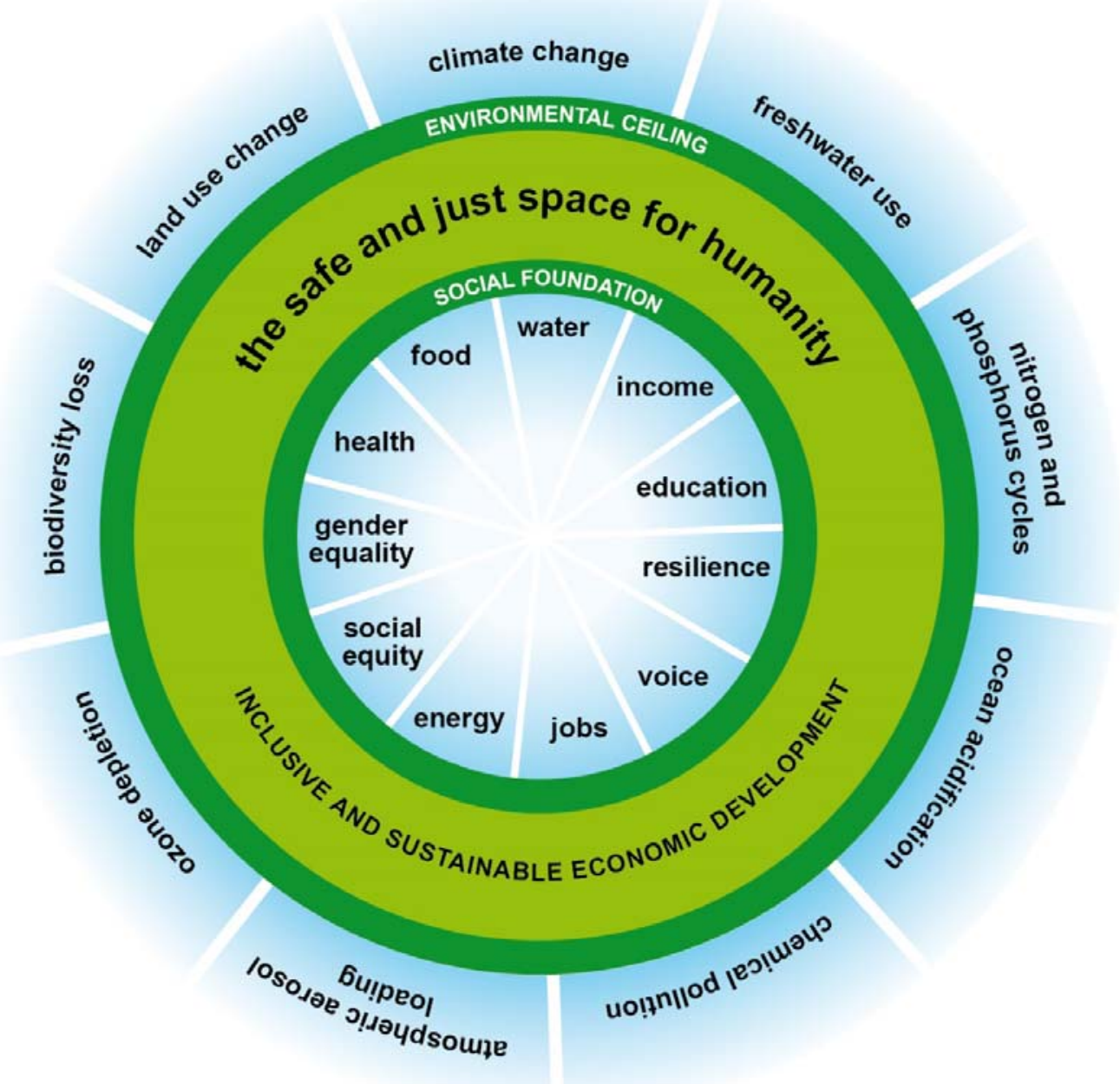

Fig 2: Raworth's doughnut, illustrating 'a safe and just space for humanity to thrive in'. This combines a set of 11 'social foundations' within the limits of a set of nine 'environmental constraints'. From Raworth (2012).

With those social foundations - which include elements such as 'social equity', 'health' and 'food' there is a conceptual return to the interests of system dynamics but also a conceptual return to the perspective of the founding works of global modelling, the analysis for the Club of Rome that 
integrates physical and socio-economic factors (Forrester, 1971; Meadows, et al., 1972). This integration of factors is typical of system dynamics, typical of global modelling (see Fig. 4). But it also - returning again to the discussion around Fig. 1 - illustrates some of the additional roles that a model can fulfil. These are explored in the next section.
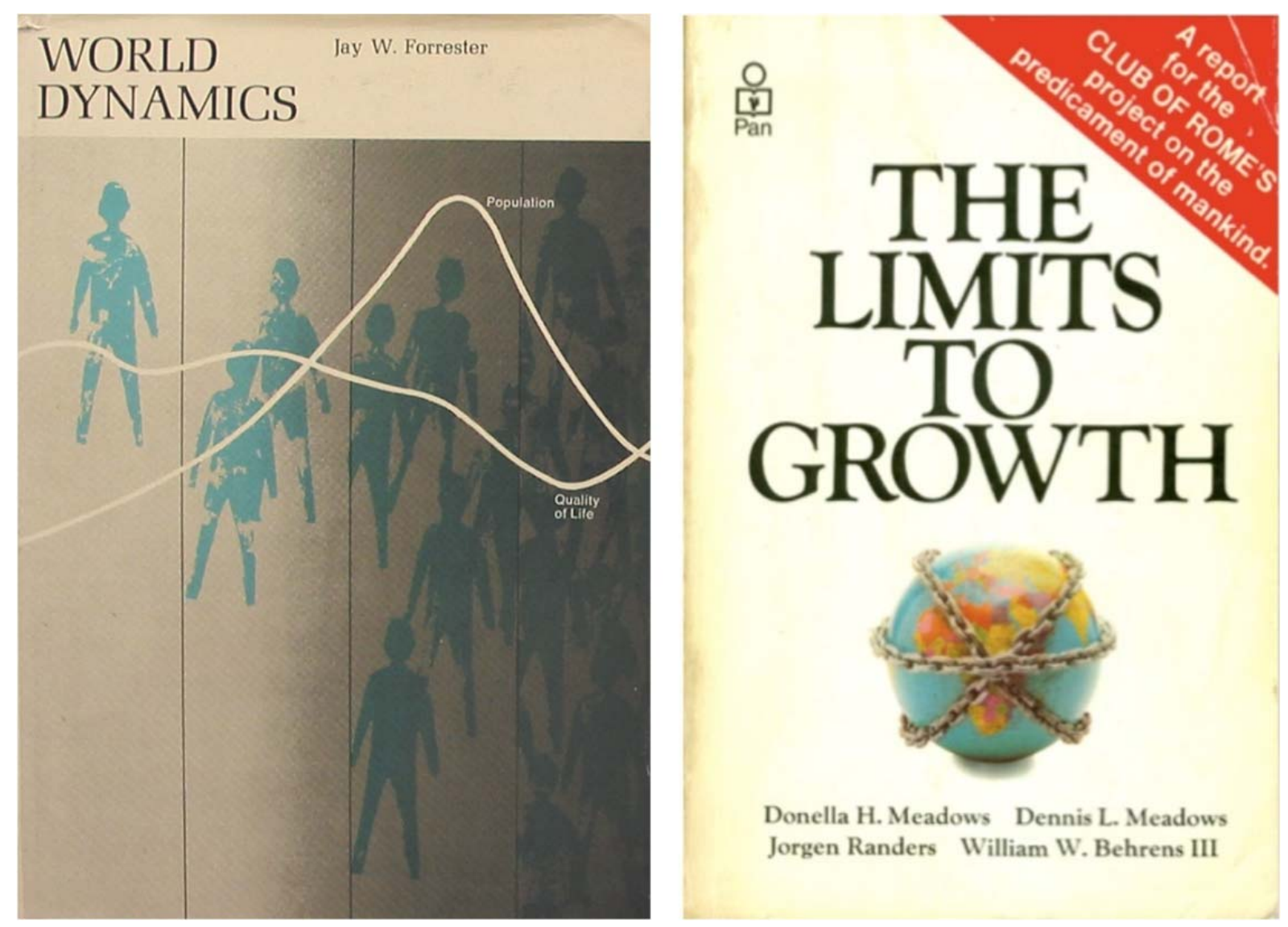

Fig. 3: Book covers of the works constituting the 'CoR Studies': Forrester (1971) and Meadows et al. (1972).

\section{SYSTEM DYNAMICS AND GLOBAL MODELLING}

This section revisits the 1970s to consider the two system dynamics books which laid the groundwork for global modelling studies, reminding readers of both hostile and supportive responses to them.

\section{The Club of Rome Studies}

The link between the field of system dynamics and global modelling can be seen to have been established by two publications: 'World Dynamics' and 'The Limits To Growth' (respectively, Forrester, 1971; Meadows, et al., 1972). The story of the creation of these works has been told elsewhere (Forrester, 1992; de Steiguer, 1997; Lane, 2007; Meadows, 2007) and detail is not appropriate here. Nor is it necessary to try to unravel the separate effects of each; responses to them came 'out of phase' and with overlap. Both attracted sales in the millions and significant comment well beyond academia. Playing on their status in establishing the area, and because of 
their roots in the Club of Rome, in this paper the pair are referred to collectively as the 'CoR studies' (see Fig. 3). ${ }^{2}$ The point here is twofold. First, that the CoR studies involved modelling which explores the interaction between effects resulting from purely natural, physical mechanisms and the effects of human behaviour; the first influenced the second and the second influenced the first in a complex web of feedback effects (see Fig. 4). Second, that this challenged the aspirations, assumptions and worldviews dominant at the time.

The CoR studies play a key part in the history of system dynamics. However, the field's experience with respect to global modelling is decidedly mixed. These studies had a very high profile, attracted wide attention ${ }^{3}$ and inspired public discussions, e.g. "... the social impact of [The Limits To growth] has never been equalled" (de Steiguer, 1997, p. 135). This looks like the best thing that ever happened to the field. However, the reverse can be argued. The lingering - frequently false reputation of these studies and their effect on the aspirations of system dynamicists sometimes make the CoR studies feel like the worst thing that ever happened to the field.

Part of the problem is the matter of the insights that these books offered. This related more generally to the system dynamics concept of 'policy insight', something explored in more detail previously in this journal (Lane, 2012). This is discussed further below.

In making the link from Lade et al. (and the other papers in this special issue) to these works, it is important to be clear that 'climate change', temperature increases, sea level rise, indeed, many key features of current concerns about our effect on the planet, do not feature in either of them. What justifies the link is a two-fold connection. First, these works took a systems view and so considered the interaction of physical and social factors in relation to the planetary system. Second, that in broad, conceptual terms they challenged assumptions by concluding that unlimited growth powered by reinforcing loops was implausible because the consequential awakening of limiting effects and their associated balancing loops was inevitable; "nothing grows forever; all reinforcing growth processes must eventually encounter limits to their growth" (Lane, 2012, p. 593). Forrester summarised the key insight of 'World Dynamics' as; "Limits are inevitable. If we evade one and continue growing, we will run into another. We don't have the option to grow forever ... Our only option is to choose our own limits, or let nature choose them for us" (Forrester quoted in Meadows, 2007, p.193). One can therefore argue that the subsequent uncovering of these other deleterious consequences of growth, these new feedback effects, are conceptually consistent with the core insight that exponential growth is implausible and unsustainable because of the balancing feedback resulting from the interaction of the various factors.

The reactions to the CoR studies are interesting yet challenging to consider. Two perspectives are available. First are the reactions at the time, considered in the next sub-section. Second are the reactions still encountered today, discussed subsequently.

\footnotetext{
${ }^{2}$ Subsequent work in this area was also supported by the Club of Rome so here 'CoR Studies' should be read as 'the founding, or core, Club of Rome Studies'.

${ }^{3}$ Somewhat discomfortingly, Forrester enjoyed telling the story of the priest from the U.S. National Council of Churches who had come across World Dynamics via an article in Playboy magazine - presumably a reference to Koff (1971) - and he recorded that publication in Forrester (1992). This author once challenged Forrester as to whether, as the latter claimed, this magazine constituted a 'politically neutral' platform.
} 


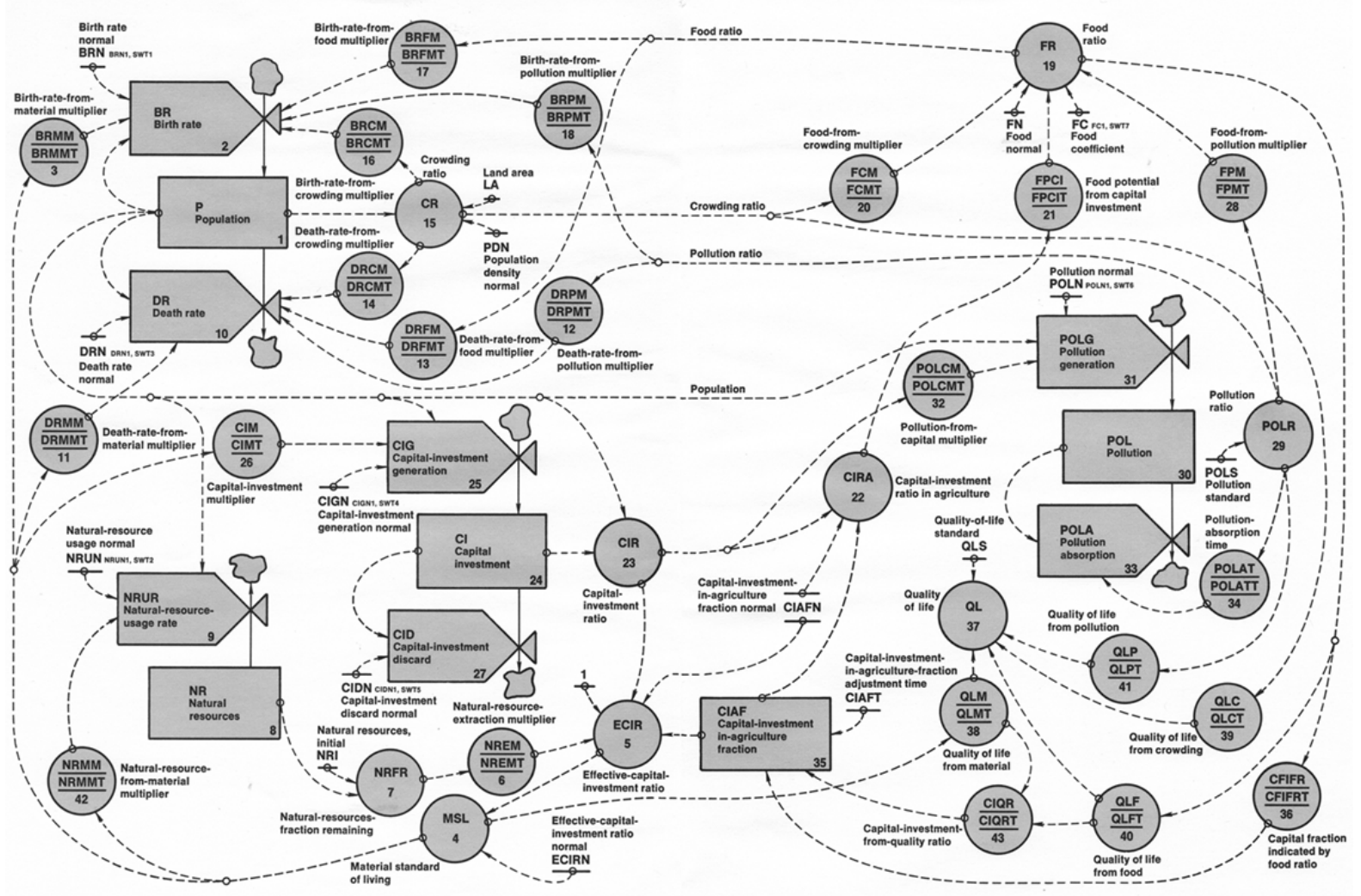

Fig. 4. Stock/flow diagram of the system dynamics model used in World Dynamics. Note the presence and interaction of purely physical factors ('NR Natural resources', 'LA Land area') and those resulting from social factors ('P Pollution', 'FR Food ratio', 'QL Quality of life'). From Forrester (1971). Compare with Fig. 2.

\section{Initial Reactions to the CoR Studies}

The CoR Studies were published in 1971 and 1972. They were the object of broad, serious and sometimes extremely acrimonious debate. The reasons for this relate to the ability of global models to challenge deeply-help ideas and worldviews.

Critical assaults on their findings were fast in their appearance. A few examples suffice to give the flavour of what occurred almost half a century ago. Economist William Nordhaus offered - amongst other elements - detailed criticisms of features of the modelling via an academic journal (Nordhaus, 1973). In the 'quality press', The New York Times provided an all-out assault (Passell, et al., 1972). Its review deems the book an "empty and misleading work" which offers only "technical chicanery", an example of "public-relations stunts which imply a false inevitability of doom". Cole at al. (1973) attacked the studies from an impressive variety of policy analysis-related angles, whilst Bloomfield (1982; and later 1986) is equally commodious in his concerns, though generally more philosophical, arguing that Forrester is always rejecting of criticisms using a variety of strategies and being particularly concerned that "Forrester talks about fundamental laws of nature and the social sciences" (Bloomfield, 1982, p.13). Nordhaus went for a re-match, upping the critical rhetoric a notch or two (the title is a film reference - perhaps inevitably, one to which time has not been kind); detailed, hectoring and still seeming to have trouble connecting with the stock/flow formulation and dynamic nature of the work he criticises (Nordhaus, 1992). 
These are but a small selection of the criticism of the CoR studies. More, colourful pieces are available - e.g. the very idea of limits to growth was rejected as antithetical to the American worldview by a US President, no less (Reagan, 1983). However, the above sample gives a sense of this side of the reaction.

It bears saying again (and again) that the CoR studies did not forecast. Instead they offer the kind of 'policy insight' that has been central to system dynamics from its beginning (Forrester, 1961). However, as argued previously (Lane, 2012), such insights are easily taken as forecasts, no matter how clear the statements to the contrary. Part of the reaction to the CoR studies clearly derives from the fact that a clear grasp of that system dynamics idea is lacking from (or has not adequately been conveyed into) the general discourse about these works.

The debate was not, however, one-sided. Meadows had a responding chapter in the Cole et al. collection (Meadows, et al., 1973) and Forrester did respond to the first Nordhaus piece (Forrester, et al., 1974). Perhaps the most substantive response to the critiques has been that so many of those involved in the original project refused to be frightened off but rather stayed with it, publishing further work in attempts to offer more granularity, explain their methodology and repeatedly update their ideas (Meadows \& Meadows, 1973; Meadows, et al., 1974; Meadows, et al., 1982; Meadows \& Robinson, 1985; Meadows, et al., 1992; Meadows, et al., 2004; Randers, 2012). A very important element of this has also been attempts to write for the popular press and in a manner which related to broader concerns about the state of the planet (Meadows, 1991; Meadows, 1996; Maxton \& Randers, 2016).

\section{The Cassandra Effect - Bardi's Thesis}

Given both the volume and nature of the material available - and its importance for the reputation of the field - it is, perhaps, hard for a system dynamicist to take a cool, measured view of the initial reaction to the CoR studies. A broad account of these debates is offered by McCutcheon (1979) but a more recent one is that of Ugo Bardi, the latter existing as both an evolving website and a book (2011a; 2011b). This view - that of a Professor of Physical Chemistry at the University of Florence offers the insights of someone who is, from the system dynamics perspective, an expert but still very much an outside observer. Whilst it appears to concentrate just on 'The Limits To Growth' the work actually draws from the whole experience of the CoR Studies. His thesis is interesting.

Bardi examines the reactions to the CoR studies in considerable detail. For example, it is Bardi who first pointed out quite how odd the paper by Nordhaus (1973) was. Today, as a useful exercise in understanding and interpreting model formulation, system dynamicists are rightly encouraged to read this piece and then to read the response by Forrester and two of his colleagues, their patient unpicking of the mis-understandings and straightforward errors regarding the underlying model (Forrester, et al., 1974). However, Bardi offers two striking observations. First, that Nordhaus' paper contains two other elements: an ad hominem attack on Forrester for his arrogance and an armwavingly broad criticism of even attempting to model the global system. The former is, perhaps, a matter of how one choses to comport oneself in scholarly discussions but the latter is worth remembering given that Nordhaus himself apparently thought the general idea of global modelling sufficiently plausible to spend decades working in very much the same area, arguing publically against climate change sceptics (Nordhaus, 2012) and achieving the supreme success measure in consequence (Royal Swedish Academy of Sciences, 2018). Bardi's second point is that it is simply strange that the Nordhaus critique was published in the Economic Journal whilst the well-tempered (in two senses) rejoinder appeared in Policy Sciences the following year. Why, Bardi wonders, was 
the Forrester et al. piece not published in the same journal? Indeed, why was Forrester not given the right of reply to Nordhaus' piece at the time and in that very journal?

That second observation plays into Bardi's general thesis. He argues that, since their publication, a bizarre legend has grown up around the CoR Studies. Anyone whose knowledge of the studies was restricted to that legend would have to be forgiven for thinking that they gave a specific headcount for the global population on 14th January 2018, or a price to the nearest penny for Magnesium in September 2025, or that humanity was condemned to irresistible collapse, the Doomsday knell ineluctably inked onto a wall-calendar. Bardi writes; "In the late 1980s, all that was remembered of the LTG book ... was that it had predicted some kind of catastrophe at some moment in the future" (Bardi, 2011a).

Bardi argues that today, the view that is widely held of the CoR Studies is heavily clouded in myths. These myths concern what the studies said (planetary destiny as Götterdämmerung - on a precise date), how they were received (instant and universal rejection on first publication), and why they can be ignored (see previous, hence: why waste more time on ludicrous nonsense?). In Bardi's opinion, people have forgotten what these studies said and how much of what was in them was correct. Behind these myths he sees lurking resistance to ideas which challenged cherished worldviews concerning the benefits of economic growth, or which challenged the power relations invested in the machinery of that growth - capitalists, corporations, the usual suspects. The link to Fig. 1 is clear - with the addition that there was resistance to the 'heresies', the worldview challenge that these books offered.

Drawing on classical allusion, he sees a reaction akin to that to Cassandra. Bardi believes that the ideas fell victim to the usual destiny of those who, like Cassandra, tell inconvenient and heretical truths: they are traduced and ignored.

\section{MODERN PERSPECTIVES}

If the CoR Studies have generally been treated like Cassandra - denigrated and not taken seriously where does that leave system dynamics and global modelling? This section considers the modern perspective on these efforts.

\section{Modern Acceptance?}

In fact, the down-cast perspective of the previous section can be deprecated to a considerable degree - if the right perspective is adopted. Today, there is considerable acceptance of the CoR Studies: first, of their core ideas, or related ideas, or of ideas developed as a consequence of them; second, of the founding works themselves.

Part of that necessary perspective is the notion that a core idea of the CoR Studies is the interaction of physical and human effects at the global level. Large swathes of the field of global modelling take this approach. Hence the view that, "Forrester's insights on the aim of caring for the environment and the need to make trade-offs between long-term versus short-term effects have an important place in environmentalist thinking today and his original model is the founding work of global modelling" (Lane, 2007, pp. 107-8, after de Steiguer, 1997). The ideas of the CoR Studies have been taken up and extended in an array of publications. Values and beliefs, mental models and worldviews have been changed. A few examples illustrate this.

Wackernagel et al. (2002) consider sustainability of human activity using modern data and conclude that the stocks that support human activity - fish population, groundwater etc. - have been overconsumed and over-degraded. The carrying capacity of the planet has been over-shot. Lenton et al. 
(2008) offer a similar analysis but focus on the concept of 'tipping points' in the Earth's climate system. This concept - very familiar to any system dynamicist - is used both to issue warnings but also as a means of focusing policy efforts aimed at changing system behaviour.

Similar arguments are found in the work of Rockström et al. (2009) cited earlier. The key difference is that they then propose a framework for the different effects that humanity is having on the ecosystem, and that that framework is aimed at tackling these effects in an integrated manner.

These are examples of the ideas of the CoR Studies being used and extended. Given Bardi's diagnosis of the parlous state of the reputation of the CoR Studies, perhaps it must simply be accepted that even if the field of system dynamics receives no credit, at least the message was delivered; consolation comes with a thought from the English biologist Thomas Henry Huxley, speaking in support of Darwin theory of evolution; "...it is the customary fate of new truths to begin as heresies" (Huxley, 1880, p. 1). But such self-effacement is not completely necessary: the founding works themselves are now the subject of re-assessment.

Eastin et al. (2011) consider the debates around the CoR Studies to learn about how to address

the related issue of climate change. Turner draws on work published in an academic journal

(Turner, 2008) to name names in arguing very publically that 'Limits to Growth was right',

adding; "So far, Limits to Growth checks out with reality" (Turner \& Alexander, 2014).

Rome (2015) considers key works that created the idea of 'sustainability' and places 'The Limits To Growth' amongst his five. His title merits quoting here: "The launch of Spaceship Earth (five prescient classics that first made sustainability a public issue in the 1960s and 1970s)". Lastly, a study for the UK's Government Office for Science endorses the CoR Studies as a sound example of 'illustrative modelling' (Government Office for Science, 2018).

This is not to say that the reassessment has been universal. Nevertheless, today there is a more balanced view of the CoR Studies, possibly indicating a partial acceptance of this work. But there is one final perspective to consider.

\section{The Anthropocene Triumph?}

Arguably a great achievement of the CoR Studies in terms of changing worldviews is 'The Anthropocene', the idea that the Earth is in a new geological epoch which is the result of human activity.

Who is saying this? Geologists. In August 2016 the 'Working Group on the Anthropocene' - an official expert group of the Sub-commission on Quaternary Stratigraphy, part of the International Union of Geological Sciences - voted in favour of the adoption of 'Anthropocene' as an official term (Carrington, 2016). The concept is not unproblematic - for a further discussion see Lane (2016) - but the core idea is clear. The proposed start date for the epoch is 1950. This is based primarily on the presence of radioactive elements released by nuclear weapons testing but also embraces soot emissions from power stations, the accretion of bones from domesticated chickens and the spread of plastic-based pollutants (Waters, et al., 2016).

The Anthropocene is a new geological epoch that results from human activity. This is a significant acceptance of the central CoR Studies idea that physical and human factors interact, the sort of change in worldview illustrated in Fig. 1 which is distinctive of global modelling. It also demonstrates a move from an exogenous to an endogenous perspective. As well of being of great interest to system scientists generally (Ison, 2016) this triumph should be a comfort to system dynamicists. After all of the troubles and travails in the reception and reputation of the CoR Studies, maybe it worked out in the end. Pity about the poor state of the planet... 


\section{CLOSING OBSERVATIONS AND LINGERING QUESTIONS}

Global modelling has some distinct features: it links natural and social phenomena and it is capable of challenging and perhaps shifting some of our key assumptions about our place on the planet and how it is possible for us to live. These features continue to be important for the field of system dynamics. These operate at very different levels.

Global modelling - derived from the CoR Studies - has unearthed what are arguably the most important feedback loops seen to be operating on planet earth. By arguing for interactions between physical and human effects, global modelling helps people grasp the extent of their responsibility for the condition of the Earth. This raises a broader, methodological point. It has been argued in detail elsewhere in this journal (Lane, 2000) that system dynamics is not a deterministic method partly because the whole purpose of modelling is to decide what one might do differently to cause 'the system' not to behave as it might otherwise do. The CoR Studies accomplished this in a somewhat peculiar way since one of their effects was to highlight a set of policy issues for which there was then no 'owner'. That humanity has struggled to erect credible and effective structures of global governance to take on these policy issues is less important than the fact that the acknowledgement of the endogeneity of the underlying effects has been the subject of such an attempt at all. Global modelling continues in this vein.

In fact, so successful have the 'endogenised' insights of the CoR Studies become that one wonders whether a longer version of Huxley's comment merits consideration:-

"History warns us, however, that it is the customary fate of new truths to begin as heresies and to end as superstitions ..." (Huxley, 1880, p. 1).

What would 'superstition' look like in the case of global modelling? What can be seen is a certain 'taking for granted-ness' of the insights created by the CoR Studies - taken for granted to the extent that one encounters those born long after 1971/2 who simply cannot understand how anyone could ever have thought that unlimited growth was plausible. Indeed, some refuse to believe that such individuals could possibly have existed. That raises a lingering question of whether such attitudes matter. Perhaps they are a measure of our success, a manifestation of the Anthropocene insight being very deeply and convincingly internalised as a worldview. Perhaps. But an inability to understand the worldview of others - even whilst not agreeing with it - is surely a deficiency. It is historically deficient since it is a matter of record that the idea that growth is the answer certainly was very widespread in the post-war period, indeed, it is a powerful force in the world today (Ketcham, 2017). Second, it is deficient in terms of ability to influence. It is surely unhelpful to become stuck in some Lakatosian world in which there are core assumptions which are not only removed from the possibility of refutation but which might be so deeply held that one has forgotten that the assumptions were ever made. The cycle shown in Fig. 1 is broken in such a situation. Moreover, the ability to see others' way of viewing things is known to be useful in the process of persuasion (Rouwette, et al., 2011), so if global modelling aspires to have an effect on others it might be useful first to understand how they see the world. In this sense the results of the CoR Studies must never be allowed to degrade to the level of superstition: the rigours of scientific modelling and the flexibility of thinking which it can enable should always be at hand.

A final lingering question is this: were the CoR Studies the best or the worst thing that ever happened to the field of system dynamics? They provided the most public exposure ever of system dynamics, drew attention (albeit positive and negative) from the most senior people the field has 
ever engaged with, and provide a model, a goal, to which Forrester and our own sense of vocation would have us all aspire. 'Best' is surely the answer.

The alternative view is that the experience with the CoR Studies was the worst thing that ever happened to the field. Now cast out of its Edenic realms, system dynamicists long for the same level of attention and importance. They almost feel a sense of entitlement, a notion that they alone know what is really going on and deserve to be heard, not relegated to the role of Cassandra, the disparaged seer whose warnings are doomed not to be listened to.

For a paper promising only initial thoughts this last question can perhaps be left to the reader to ponder. As outlined here, system dynamics might have started by offering heresies but has contributed immeasurably to the field of global modelling. How system dynamicists wrestle with its legacy is a challenge to which they must rise.

What is clear is that whilst global modelling may have provided the system dynamics field with both 'the best of times and the worst of times' it has been of immense significance to that field. It has contributed to profound and widespread shifts in beliefs, cherished assumptions and worldviews. It also has immense significance for all living on planet Earth. It is an area of application that should be both celebrated and pursued with vigour.

\section{REFERENCES}

Bardi U. 2011a. How "The Limits to Growth" was demonized. Posted on September 15th http://cassandralegacy.blogspot.co.uk/2011/2009/cassandras-curse-how-limits-togrowth.html.

Bardi U. 2011b. The Limits to Growth Revisited. Springer: Heidelberg.

Bloomfield B. 1982. Cosmology, Knowledge and Social Structure: The case of Forrester and system dynamics. Journal of Applied Systems Analysis 9: 3-15.

Bloomfield BP. 1986. Modelling the World, the social construction of systems analysts. Basil Blackwell: Oxford.

Carrington D. 2016. The Anthropocene Epoch: Scientists declare dawn of human-influenced age. The Guardian newspaper, 29th August.

Cole HSD, Freeman C, Jahoda M, et al. (eds.). 1973. Models of Doom. Universe Books: New York.

de Steiguer JE. 1997. The Age of Environmentalism. McGraw-Hill: London.

Dearing JA, Wang R, Zhang K, et al. 2014. Safe and just operating spaces for regional social-ecological systems. Global Environmental Change 28: 227-238.

Eastin J, Grundmann R and Prakash A. 2011. The two limits debates: "Limits to Growth" and climate change. Futures 43: 16-26.

Forrester JW. 1961. Industrial Dynamics. MIT Press: Cambridge, MA.

Forrester JW. 1971. World Dynamics. Wright-Allen Press: Cambridge, MA.

Forrester JW. 1992. From the Ranch to System Dynamics. In Management Laureates: A collection of autobiographical essays (vol. 1) ed. AG Bedeian, JAI Press: Greenwich CT; pp. 335-370.

Forrester JW, Low GW and Mass NJ. 1974. The debate on world dynamics: a response to Nordhaus. Policy Sciences 5: 169-190.

Government Office for Science. 2018. Computational Modelling: Technological Futures (authors: Walport, M., Calder, M., Craig, C., Culley, D., de Cani, R., Donnelly, C., Douglas, R., Edmonds, B., Gascoigne, J., Gilbert, N. Hargrove, C., Hinds, D., Lane, D. C., Mitchell, D., Robertson, D., Rosewell, B., Sherwin. S., Wilson, A.). www.gov.uk/government/publications/computationalmodelling-blackett-review: Available from.

Huxley TH. 1880. Editorial - The Coming of Age of the Origin of Species: A lecture delivered at the Royal Institution, Friday March 19. Nature XXII: 1-4. 
Ison R. 2016. Governing in the Anthropocene: What Future Systems Thinking in Practice? Systems Research and Behavioral Science 33: 595-613.

Ketcham C. 2017. The Fallacy of Endless Economic Growth. Pacific Standard Magazine 30: Available from: https://psmag.com/magazine/fallacy-of-endless-growth.

Koff RM. 1971. An End To All This. Playboy July: pp: 112, 114, 206-208.

Lade SJ, Anderies JM, Cornell S, et al. 2017. Working Paper: Feedbacks between loss of biosphere integrity and climate change. Modelling Sustainability Pathways: Bridging science, policy and society: Circulated and presented at the Seventh European System Dynamics Workshop, at NOVA University Lisbon, Portugal (31st May - 2 June).

Lane DC. 2000. Should System Dynamics Be Described As A 'Hard' Or 'Deterministic' Systems Approach? Systems Research and Behavioral Science 17: 3-22.

Lane DC. 2007. The Power of the Bond Between Cause and Effect: Jay Wright Forrester and the field of system dynamics. System Dynamics Review 23: 95-118.

Lane DC. 2012. What Is A 'Policy Insight'? Systems Research and Behavioral Science 29: 590-595.

Lane DC. 2016. 'Till the muddle in my mind have cleared awa': Can we help shape policy using systems modelling? Systems Research and Behavioral Science 33: 633-650.

Maxton G and Randers J. 2016. Reinventing Prosperity: Managing economic growth to reduce unemployment, inequality, and climate change - A report to the Club of Rome. Greystone Books: Vancouver.

McCutcheon R. 1979. Limits of a Modern World: A study of the 'limits to growth' debate. Butterworth: London.

Meadows DH. 1991. The Global Citizen. Island Press: Washington, DC.

Meadows DH. 1996. Envisioning A Sustainable World. In Getting Down to Earth, Practical Applications of Ecological Economics eds. R Costanza, O Segura and J Martinez-Alier, Island Press: Washington DC; pp.

Meadows DH. 2007. The History and Conclusions of The Limits to Growth (edited post mortem by Dennis Meadows from an unpublished original). System Dynamics Review 23: 191-197.

Meadows DH and Robinson JM. 1985. The Electronic Oracle: Computer models and social decisions. John Wiley: New York.

Meadows DH, Richardson J and Bruckmann G. 1982. Groping In The Dark. Wiley: Chichester.

Meadows DH, Meadows DL and Randers J. 1992. Beyond the Limits: Confronting global collapse, envisioning a sustainable future. Earthscan: London.

Meadows DH, Randers J and Meadows DL. 2004. Limits to Growth: The 30-year update. Earthscan: London.

Meadows DH, Meadows DL, Randers J, et al. 1972. The Limits to Growth: A report for the Club of Rome's project on the predicament of mankind. Earth Island: London.

Meadows DL, Meadows DH, Randers J, et al. 1973. A Response to Sussex. In Models of Doom eds. HSD Cole, C Freeman, M Jahoda and KLR Pavitt, Universe Books: New York; pp. 217-240.

Meadows DL, Behrens WW, Meadows DH, et al. 1974. Dynamics of Growth in a Finite World. WrightAllen Press: Cambridge MA.

Meadows DL and Meadows DH (eds.). 1973. Towards Global Equilibrium. Wright-Allen Press: Cambridge, MA.

Nordhaus WD. 1973. World dynamics: measurement without data. Economic Journal 83: 1156-1183.

Nordhaus WD. 1992. Lethal model 2: the limits to growth revisited. Brookings Papers on Economic Activity 2: 1-59.

Nordhaus WD. 2012. Why The Global Warming Skeptics Are Wrong. The New York Review of Books LIX: March 22, 2012 Issue.

Passell P, Roberts M and Ross L. 1972. The Limits to Growth (Sunday Book Review). New York Times 2 April: BR1. 
Randers J. 2012. 2052: A global forecast for the next forty years (a report to the Club of Rome commemorating the 40th anniversary of 'The Limits to Growth'). Chelsea Green: White River Junction VT.

Raworth K. 2012. A Safe and Just Space for Humanity: Can We Live Within the Doughnut? Oxfam Discussion Papers: Oxford.

Reagan R. 1983. Remarks at Convocation Ceremonies at the University of South Carolina in Columbia. September 20. Online via the Ronald Reagan Presidential Library and Museum: www.reaganlibrary.gov/research/speeches/92083c.

Rockström J, Steffen W, Noone K, et al. 2009. Planetary Boundaries: Exploring the Safe Operating Space for Humanity. Ecology and Society 14: 32. [online].

Rouwette EAJA, Korzilius $\mathrm{H}$, Vennix JAM, et al. 2011. Modeling as Persuasion: The impact of group model building on attitudes and behaviour. System Dynamics Review 27: 1-21.

Royal Swedish Academy of Sciences. 2018. The Prize in Economic Sciences 2018: William D. Nordhaus and Paul M. Romer for integrating innovation and climate with economic growth. Press Release available from https://www.nobelprize.org/uploads/2018/2010/presseconomicsciences2018.pdf.

Turner G and Alexander C. 2014. Limits to Growth was right. New research shows we're nearing collapse. The Guardian newspaper, 2nd September.

Turner GM. 2008. A comparison of The Limits to Growth with 30 years of reality. Global Environmental Change, special issue on Globalisation and Environmental Governance: Is Another World Possible? 18: 397-411.

Wackernagel M, Schulz NB, Deumling D, et al. 2002. Tracking the ecological overshoot of the human economy. Proceedings of the National Academy of Science 99: 9266-9271.

Waters CN, Zalasiewicz J, Summerhayes C, et al. 2016. The Anthropocene is functionally and stratigraphically distinct from the Holocene. Science 351: 137-149. 